\title{
EL PONTIFICIO COLEGIO ESPAÑOL DE SAN JOSÉ DE ROMA, OBRA SIGNIFICATIVA DE MANUEL DOMINGO Y SOL
}

DOI: https://doi.org/10.52039/seminarios.v55i191.506

Lope RuBio PARRAdO 1

En este número dedicado al Beato Manuel Domingo y Sol en el centenario de su muerte hemos querido aunar: espíritu, misión y proyecto.

Nos pareció que una de las obras más significativas que revelaban su carácter sacerdotal y eucarístico-reparador era el Pontificio Colegio Español de Roma. El autor, no sólo conocedor eminente, por sus trabajos y estudios sobre el tema histórico, sino apasionado por la obra del Colegio a la que dedicó muchos años de su vida, o sea, oración, silencio, buen hacer, vinculación con al santa sede, coordinación de los colegios pontificios romanos, orientación y acompañamiento a los sacerdotes colegiales, paciencia para con todos y, hasta, infarto, expone con claridad y el seny del fundador Is peripecias de la fundación del colegio.

Ahí no termina el trabajo, sino que para el lector será de sumo interés ver cómo se rige este collegium, qué persigue, cómo se maneja en la Roma del Papa. Un trabajo extraordinario henchido de amor a la Iglesia y a la Hermandad de Mosén Sol.

1 Es sacerdote operario diocesano. Ha sido director general de la Hermandad y en los años de servicio en ese cargo estimuló la creación de institutos de pastoral vocacional en Buenos Aires, México, Caracas, Washington y Sâo Paulo. Ha sido rector del pontificio colegio español de san José en Roma a lo largo de 14 años y actualmente es director espiritual en el seminario de la Hermandad en la ciudad de México. 
PRESENTACIÓN (74); 1 . Tuvo el instinto que crear un colegio español en Roma para el bien de España (76); 2. Causas del fracaso de otras tentativas (77); 3. Y así estaban las cosas... y así hubieran continuado (78); 4. Naturaleza del Colegio (82); 4.1. Algo más que un seminario (82); 4.2. El origen (82); 4.3. Pensando en la fraternidad sacerdotal (83); 4.4. Proyecto pastoral inmediato y universal (83); 4.5. Unión del clero (83); 4.6. No sólo una utopía (84); 4.7. Miembros de una familia (84); 5. Vida interna (85); 5.1. Criterios (85); 5.2. Medios (85); 5.3. Responsabilidad compartida (86); 6. Pontificio Colegio Español instrumento eficaz para la renovación del clero y de los seminarios españoles (87); 6.1. En el aspecto científico (88); 6.2. En el campo formativo (89); 6.3. En la espiritualidad (89); 7. Más de un siglo de servicio (90); 8. El colegio español de Roma, obra significativa del Beato Manuel Domingo y Sol (92).

\section{PRESENTACIÓN}

La razón existencial de Mosén Sol estuvo íntegra en dar a la Iglesia muchos y santos sacerdotes. Así lo declara él mismo y así sintetizan varios de sus biógrafos la vida y el ministerio del Beato Manuel Domingo y Sol, Mosén Sol, fundador del Colegio de San José en Roma. Recordemos que él mismo había escrito: Mi intento primero y mi ambición en la Obra (de las

\footnotetext{
2 Para todo lo relacionado con el Colegio Español de Roma, puede verse la siguiente documentación y obras. En estos fondos se apoya todo el contenido de lo escrito:

- En el Archivo del Colegio Español de Roma (RACE) los Libros de Crónicas;

las Memorias enviadas a la Congregación para la Educación Católica y a los Arzobispos y Obispos de España y los Catálogos de 1892-1967 y 1892-1992.

- Torres Sánchez, A.: Vida de don Manuel Domingo y Sol. Tortosa, 1934

- Mártil Barbero, G.: Manuel Domingo y Sol, apóstol del sacerdocio. Madrid,1942

- AAVV.: Recuerdo de unas fiestas (Bodas de oro del Pontificio Colegio Español de San José de Roma. Roma, 1942

- Rubio Parrado, L.: El Pontificio Colegio Español de Roma. Historia y documentos. Roma, 1975

- Martín Hernández, F. - Rubio Parrado, L.: Mosén Sol. Salamanca, 1978

- Javierre Ortás, J.M.: Reportaje a Mosén Sol. Madrid, 1987

- Andrés Hernansanz, J. de.: El Pontificio Colegio Español de San José. Cien Años de historia .Roma, 1992

- Rubio Parrado, L. - Martín Hernández, F. - Andrés Hernansanz, J. de.: Sacerdotes Operarios Diocesanos. Aproximación a su historia. Salamanca,1996.
} 
vocaciones) era multiplicar las vocaciones ${ }^{2}$.

Muchos y santos sacerdotes, sí; pero también los quería cultos; él dirá instruidos. Porque además de pobres, los seminaristas españoles de su tiempo y el mismo clero sufrían una seria anemia cultural debido a una serie de circunstancias que no son del caso especificar ahora por estar suficientemente estudiadas en diversas publicaciones y por distintos autores.

Manuel Domingo y Sol había seguido con holgura sus estudios de filosofía, teología y derecho en el seminario diocesano de Tortosa y ya sacerdote joven, se doctoró en teología en la universidad eclesiástica de Valencia y consiguió el grado de bachiller en artes por la universidad pública de Barcelona ${ }^{3}$.

Nos consta cómo cuida sus clases de religión en el instituto de segunda enseñanza de su ciudad; preparaba y escribía sus sermones y fervorines; se dedica en cuerpo y alma a trabajar con los jóvenes y con los obreros. Fue un polifacético escritor de artículos; no fue un intelectual académico en el sentido actual del término, pero sí era un fino observador de su entorno, un conocedor exhaustivo de la juventud levítica, de los aciertos y fallos de los programas formativos no sólo académicos sino de las diversas áreas formativas a juzgar por las descripciones que él mismo no ha dejado de la situación de los seminarios de su tiempo. Le dolía la baja consideración de que gozaban los sacerdotes debido a su escasa formación académica llena de lagunas y a su poca altura en valores humanos.

Como resumen de su personalidad cultural nos parece muy acertado el juicio que en este aspecto emite de él un conocedor de su obra:

Concedamos que no fue Don Manuel ni escritor clásico, ni un erudito, ni un pensador genial. Pero tenía clarísima inteligencia y sabía manejar la pluma con muy genial garbo. En sus cartas, acaso el más fiel espejo de su alma hay, como en las de Santa Teresa de Jesús, espontaneidad, candor, frescura de ingenio, sana alegría, oportunidad y, sobre todo, discreción suma para dosificar afectos, consejos, advertencias y reprensiones.

No fue un orador, en el sentido moderno de esta palabra; pero en sus sermones hay orden, vigorosa argumentación, transparencia de pensamiento, unción persuasiva, a veces novedad en la expresión, y un estilo fácil, animado, insinuante y siempre acomodado a las ideas y a las circunstancias. Con igual desembarazo andaba por los caminos llanos que se elevaba de un vuelo a las cumbres de la ascética y la mística.

3 De especial interés son las obras de Cárcel Ortí, de Martín Hernández y la publicación Mosén Sol ya citada.

4 Rodríguez, A. en Torres, o c, XIII. 
Adueñándose de los corazones, les comunicaba sus propios afectos, y con elocuencia ya dulce, ya arrebatadota, lo llevaba hacia Dios...4.

Poseía instinto y talento práctico. La creación de los Colegios de Vocaciones Eclesiásticas y el contacto directo con los alumnos le hizo comprender que con profesores deficientes el alimento intelectual no podía ser elevado. Si él con sus Operarios estaban intentando elevar la formación humana y espiritual de los seminaristas, había que empañarse seriamente en conseguir verdaderos maestros para la formación académica.

\section{TUVO EL INSTINTO DE CREAR UN COLEGIO ESPAÑOL EN ROMA PARA EL BIEN DE ESPAÑA}

Ante la situación con que se encontró, ¿Qué hacer? Mosén Sol piensa en Roma como solución. Llevar a los mejores centros de Roma a jóvenes seminaristas para que se capaciten y regresen luego como fermento de los claustros de los seminarios españoles. No sólo como profesores cualificados sino también como creadores de otras estructuras formativas y de proyector pastorales mancomunados y, ¿por qué no? germen de fraternidades sacerdotales y de intercambio de programas para el mejor mantenimiento del sacerdote en todos los ámbitos de su vida y ministerio. Es así como ya a comienzos de 1888 escribe que tuvo el instinto de crear un Colegio español en Roma para el bien de España5.

Llama la atención el hecho de que España, con el peso que entonces tenía en la geografía eclesial, llegue hasta finales del siglo diecinueve sin afrontar de forma definitiva este problema. Otras naciones de menor vigor religioso y más escasa historia e influencia contaban ya con sus colegios nacionales donde nutridos grupos de seminaristas se preparaban a conciencia para ocupar luego cargos de la mayor responsabilidad académica y administrativa en sus diócesis de origen. Incluso las iglesias de Latinoamérica contaban ya desde mediados del siglo con su Pío Colegio Latino Americano. Bien pronto, desde los tiempos de San Ignacio de Loyola creador del Colegio Romano, más tarde Universidad Gregoriana, surgen los colegios Germánico, Belga, Francés, Irlandés, Polaco, Húngaro...

Es cierto que hubo algunos intentos como el Colegio Hispano del obispo

${ }^{5}$ Años más tarde nos descubrirá el mismo don Manuel: Bien por los augurios que me hace de los futuros resultados del Colegio Español en Roma para el bien de España y honra y desarrollo de nuestra Obra en la misma, según las tuve en mis instintos desde el 1 de enero de 1888. 
Calvo y Valero en 1883, que Mosén Sol conoce y desde El Congregante informa a sus lectores de las andanzas apostólicas del prelado primero de Santander y más tarde de Cádiz. Con el obispo se escribe y con él se encuentra sin llegar a un acuerdo para conjuntar intereses a juzgar por las cartas del fundador del Colegio Español y por el comportamiento posterior del citado prelado con ocasión de la cesión del palacio Altemps a los obispos españoles para sede del colegio6.

Cabe preguntarnos, antes de entrar de lleno en la obra de Mosén Sol, en las razones por las que fracasó este primer proyecto. Manuel Domingo y Sol también se formula la pregunta y la responde años más tarde hablando a los primeros colegiales de Roma. Merece la pena conocer el texto para evitar posteriores explicaciones y entender resultados.

\section{CAUSAS DEL FRACASO DE OTRAS TENTATIVAS}

¿Cuáles eran las causas de aquellos fracasos y de aquel retraimiento a pesar de las buenas disposiciones de algunos Prelados? En la audiencia que dicho monseñor Calvo tuvo con el Papa y en la cual le expuso su pensamiento de un Seminario Español allí en Roma, le indicó, como consta en documento impreso (que envió a lo demás obispos) los reparos que algunos de éstos opusieron al pensamiento de enviar jóvenes alumnos a Roma, y que se reducían principalmente a dos, a saber, que los Seminarios de España profesaban muy sana doctrina y estaban sus estudios a la altura de los mejores, ya que de enviarlos a Roma, regresarian llenos de ínfulas de omnisciencia y que por lo tanto serían ambiciosos e indomables. A lo cual dice él mismo que el Papa le contestó, que dejando a la apreciación de los obispos lo de las dificultades pecuniarias, lo demás era praejudicium insanum, una necia preocupación. Y ciertamente que eran fútiles esas razones y más bien praejudicium insanum. Porque, ¿qué significaba aquello de que volverían envanecidos por los grados obtenidos en Roma? El mismo argumento hubiera podido hacerse a los que a obtenerlos en las famosas Universidades de España y aún del extranjero, y lo mismo respecto a los actuales alumnos de los Seminarios de España que van a recibir los grados en los Centrales. Para ello deberían desaparecer los grados académicos, canónicos, establecidos por la Iglesia a favor de los que merezcan, porque puede engendrar presunción. En cuanto a la enseñanza segura y próspera de sus Seminarios, cualquiera que ella fuese, nunca podía ser más segura, ni en España, ni en ninguna otra parte, que la expuesta a la vista de Su Santidad, ni más pujante que la de la Gregoriana, por ejemplo, dada por un profesorado compuesto de lo más selecto que la Compañía tiene en varias

6 Sobre el obispo Calvo y Valero y su Colegio Hispano, cfr. Mosén Sol o c, 272-273. 
provincias y aún naciones del mundo, y que vosotros tendréis ocasión de conocer en la de la Minerva.

Además de estos recelos revelados por el antedicho Prelado, mediaban algunos otros prejuicios que no han dejado de significársenos a nosotros mismos, al exponer nuestro pensamiento de la fundación de Colegio en Roma; tales como el que se formarían en el espíritu italiano perdiendo el vigor del espíritu sacerdotal español, cuando ese espíritu, bueno o majo, lo adquirirían por nuestra formación sin intervención alguna de los italianos; y otros como el de la distancia y estar tan separados de la mirada de los Prelados, siendo así que podían dárseles cuenta frecuente de su comportamiento, y que las distancias, hoy podemos decir, que han desaparecido. Abogado yo he conocido en mi país que para ir a Madrid a estudiar empleaba diez días en las antiguas calesas con muchos gastos y más fastidio, cuando el viaje a Roma puede hacerse hoy como viaje de recreo. ¿Qué sería antes con los que de nuestro país iban a Salamanca? Mas sin dejar de conocer o reconocer que algunas de estas razones, o como quieran llamarse o todas ellas juntas pudieran influir en la actitud de algunos, pero no es fácil de explicar por ellas su retraimiento general, y tengo para mi que las verdaderas debían ser otras y más generales.

Y la primera de ellas tal vez es debida a nuestro modo de ser hoy los españoles; no tenemos el espíritu de ambición santa y de propaganda de nuestros antiguos, estamos aferrados a lo que vemos o tenemos, como si fuera lo mejor, sin cuidarnos del movimiento que pueda observarse en otras partes, y esto lo mismo en arquitectura, que en comercio, que en literatura. No se creaba atmósfera, no se impulsaba esta idea, y estábamos estacionados, y era la única nación, fuera de Portugal que no tuviera colegio en Roma, a pesar de tener tan cerca Francia, que amén de sus seminarios mayores y menores, y aún universidades, hacian fortuna en Roma con Colegios que establecieron de esa nación. La segunda causa, a mi parecer, es la indicada, aunque veladamente por el Sr. Calvo al Papa; vivíamos envanecidos con nuestras antiguas glorias teológicas, como si las poseyéramos hoy todavía, desconociendo o queriendo desconocer el desnivel en que nos encontramos de otras partes, y que tan fácilmente hubiéramos podido observar en las obras mismas de textos de nuestros propios Seminarios, casi todas debidas a teólogos y moralistas extranjeros y contemporáneos sin contar muchísimas obras religiosas cuyo mérito era reconocido por todos.

Últimamente y quizá la principal, eran las dificultades que instintivamente se preveían para la institución de un seminario oficial en Roma, no existiendo iniciativas indiscutibles que pudieran imponerse y llevarla a cabo con aquiescencia y asentimiento general y las otras de acuerdo común respecto a la elección de la entidad religiosa o sacerdotal o individuos (o miembros) que debieran cuidarlo y dirigirlo, que pudiera llegar a merecer la

7 El texto manuscrito completo se encuentra en el Archivo de la Hermandad de Sacerdotes Operarios Diocesanos. Fundador. Escritos, Predicación, Vol. $8^{\circ}$, Doc. 52-59. La trascripción en Mosén Sol, o c, 509-510. 
confianza y aplauso de todos. Tal vez estos recelos y desconfianzas enervaban los deseos y la acción de muchos Prelados ${ }^{7}$.

No cabe duda de que la respuesta del fundador es profunda en cuanto al análisis que hace de la situación de los seminarios españoles en estos años. Del concepto que algunos obispos tenían de sus seminarios, baste recordar lo que escribía el cardenal Monecillo sobre el de Valencia al despedirse de sus diocesanos para ir a tomar posesión de la sede toledana:

De todas partes llega el crédito que bien adquirida tiene la instrucción sólida impartida a los jóvenes levitas en la escuela universitaria de Valencia, y nadie ignora la afluencia con que de varias diócesis de España acuden alumnos al Central de este arzobispado para obtener títulos académicos, que ostentan como credenciales para sus ejercicios literarios otorgada al mérito de jueces hábiles y prudentes ${ }^{8}$.

Citamos Valencia por tratarse del seminario Central en el que Mosén Sol obtiene sus grados académicos. Pero a todas las causas apuntadas por el fundador, podemos añadir otra más compleja. Un proyecto como la fundación y el sostenimiento del colegio en Roma no se puede hacer en un día, ni la puede llevar a término una sola persona por muy capaz, prestigiosa y culta que sea. Necesita el respaldo de una institución que le dé continuidad y eficacia por encima de cambios y contingencias personales.

Por ello Mosén Sol une su obra a la Hermandad de Sacerdotes Operarios por él fundada unos años antes. Es ella quien se compromete y respalda, es a ella a quien desea unir inseparablemente la fundación y desarrollo del Colegio Español de Roma. En el Decreto de la Causa de Beatificación y Canonización del ya ahora Beato Manuel Domingo y Sol se dice:

Muchos fueron los colegios y seminarios erigidos con su esfuerzo y dirigidos con su prudencia, para la promoción de las vocaciones sacerdotales, tanto en España como en Portugal, en Italia y en América, entre los cuales destaca el Pontificio Colegio Español de Roma9.

\section{Y ASÍ ESTABAN LAS COSAS... Y ASÍ HUBIERAN CONTINUADO}

8 Cfr. Boletín Eclesiástico de la Diócesis de Valencia. 20 (1892) 101.

9 El texto íntegro en Mosén Sol, o. c. 526-530. La cita en p. 529. 
La historia de la fundación del Colegio de Roma tiene una parte que se escribe en dos líneas, pero que supone años de meditación en silencio de oración y de días. Un sacerdote de una diócesis española no especialmente significativa por su extensión o renombre externo ha tenido el instinto. Se reúne con los suyos el 1 de enero de 1889 y les dice:
Y así estaban las cosas... y así hubieran continuado por mucho tiempo a pesar de las excitaciones de la Santa Sede y de irse extendiendo el sentimiento y deseo de complacerle, cuando el Señor, antes de conocer nosotros la historia de estos deseos y las causas del retardo de su realización, quiso sugerirnos el año 1889, el pensamiento de establecer una casa de nuestra obra de vocaciones eclesiásticas para jóvenes de los seminarios españoles que los obispos quieran confiarnos, o ellos prefirieran seguir sus estudios en Roma, facilitándoles los medios en cuanto estuviera de nuestra parte ${ }^{10}$.

Les deja a los suyos un año para la reflexión y para orar el proyecto. En enero de 1890 recuerda e insiste en el tema. Los Operarios son aún muy pocos. Pequeña grey para la presunción que tenemos de conquistar el mundo escribe el fundador a las monjas solicitando oraciones para su proyecto. A los Operarios les impacienta e ilusiona la idea. Todos han rezado. Mosén Sol además ha trabajado en silencio. Les recuerda nuevamente a los suyos que la formación del clero es la llave de la cosecha en todos los campos de la gloria de Dios ${ }^{11}$. Ya en otra ocasión había escrito que de la calidad de los sacerdotes dependía incluso el bienestar de una nación.

Mientras tanto, como manifiesta un comentarista actual, el organismo docente de la Iglesia española llevaba casi un siglo hundido en la atonía, se ha dejado comer el terreno por la mentalidad liberal; del seminario salen promociones sacerdotales incultas, divididas en discusiones estúpidas de carácter político. Esta carcoma intelectual acaba secando las fuentes de la espiritualidad y hace a los sacerdotes toscos y ramplones ${ }^{12}$.

Las sugerencias de los papas Pío IX y León XIII a los obispos españoles para la creación de un colegio nacional en Roma no consiguen una respuesta sólida. Las revistas religiosas La cruz y El consultor de los Párrocos estimulaban cualquier iniciativa en este sentido y apostaban por Roma. Mosén Sol habla a los suyos en términos de urgencia: urge abrir allá un colegio. Del colegio de Roma han de salir los apóstoles de las diócesis españolas.

\footnotetext{
10 RACE, Crónica, Vol. I, 362-363.

11 Javierre, J. M., Reportaje o. c., 245.

12 Archivo Hermandad. Fundador. Escritos, I, Vol. $8^{\circ}$
} 
Cárcel Ortí no duda en escribir que al episcopado español le falta organización, unidad e interés para resolver graves problemas; tan graves como el de la formación de los sacerdotes ${ }^{13}$.

En un primer momento, Mosén Sol concibió la idea como algo sencillo, humilde, un pequeño grupo de colegiales selectos de sus colegios dispuestos a recibir la formación especial que se daba en los centros eclesiásticos romanos ${ }^{14}$. Se convence y manifiesta a sus Operarios que la Hermandad era la que al parecer mejor que nadie podía producir aquel deseado movimiento de vocaciones... por constituir esto un objeto primordial suyo, por el carácter puramente sacerdotal de la misma ${ }^{15}$, excitándose en todos un deseo cada día más vivo de realizar aquella empresa cuyas ventajas iban entendiendo ${ }^{16}$.

El pensamiento del fundador se va ampliando y no tardando lo presentará el mismo a los primeros colegiales romanos:

Este pensamiento tan modesto en nuestras primeras intenciones, fue tomando un vuelo y adquiriendo una importancia tal, a consecuencia de las contradicciones que el enemigo de todo bien iba suscitando, que al realizarlo hoy se vislumbra y aparece el medio de que la providencia ha querido valerse, como el más propio, para hacer desaparecer los temores y recelos que acaso hasta ahora podían servir de pretexto. Porque esta empresa libra a los Prelados, que de veras la desean, de las ataduras y compromisos a que acaso podían creerse obligados con el establecimiento de un servicio oficial 17 .

Ya que contamos con alguna buena síntesis de la historia del Colegio y un detallado comentario de sus hechos principales ${ }^{18}$, entremos en profundidad en lo que ha supuesto para la Iglesia española el contar con 120 años de su servicio continuo para la formación del clero y para la reforma de sus seminarios. Lo hacemos precisamente en el marco de la celebración del centenario de la muerte del fundador cuya aventura humana se extendió desde 1836 a 1909.

13 Cfr. Apuntes sobre la prehistoria del Colegio Español de Roma en Mater Clementissima 1991, 31.

14 RACE, Crónica. I, 1

15 Ibidem

16 Quien escribe es el mismo que va a realizarlo como primer rector del colegio desde su fundación hasta 1909. Se trata de Benjamín Miñana.

17 RACE. Crónica, II, 363.

18 El texto completo de las consideraciones expuestas por el fundador del colegio a los primeros colegiales puede verse en Mosén Sol, o. c., 513-519. 


\section{NATURALEZA DEL COLEGIO}

Felizmente nos llegaron las mismas palabras del fundador y fielmente las transcribimos. Él mejor que nadie responde a nuestras preguntas más interesantes e interesadas. Están tomadas de sus charlas a los primeros colegiales romanos.

\subsection{Algo más que un seminario}

¿Qué significa, qué objeto se propone y viene a llenar el Colegio Español de San José en Roma?...

No es un centro de enseñanza, es el establecimiento de una casa. Esto es, un colegio en Roma, y tal aparece exteriormente el nuestro. Mas este colegio de San José significa algo más que un simple colegio, que un internado de un seminario, que un colegio español. Si sólo hubiéramos intentado un seminario oficial, obra muy laudable hubiera sido, pero no hubiera producido en nosotros el entusiasmo que nos ha animado a soportar tantos desvelos y vencer tantos obstáculos como para ello se han presentado.

Mas nuestra fundación tiene otro origen y otra base y otro objeto mayor. $Y$ por medio de ella perseguimos fines más altos; $y$ este objeto y estos fines imprimen en cada uno de vosotros un carácter muy distinto que el de meros individuos de un internado eclesiástico; y este carácter viene a imponernos mayores deberes, los cuales han de proporcionar a nosotros resultados más consoladores.

\subsection{El origen}

Esta fundación no es obra de cálculos, es fruto de nuestra Institución y tiene la misma base que la obra de los Colegios de vocaciones eclesiásticas de San José de España, cuyo objeto es cooperar a los designios de Dios apoyando las vocaciones que necesitan ayudas, alientos y cuidados.

Y al instituir este Colegio se propone, animada del mismo espíritu, producir en los jóvenes de España un movimiento hacia los estudios de Roma, facilitándoles los medios, admitiendo a cuantos el Seños nos indique con el sello de su voluntad;... desea ayudar a los jóvenes con talento que lo deseen y que sin esta ayuda no podrían realizarlo...

Es, en fin, ésta una obra propia nuestra, hija de nuestro corazón y fruto de 
nuestra vocación, la cual no sería un seminario, como lo son esos colegios o seminarios, aun los nacionales.

\subsection{Pensando en la fraternidad sacerdotal}

Pero además de ser éste el objeto y base de nuestra empresa, nos proponemos por medio de ella otros fines más altos, propios $y$ acomodados a los que tiene nuestra Hermandad. Hemos creído que esta casa pueda ser como el punto céntrico más a propósito para la reunión y afluencia de los jóvenes más distinguidos de todas las diócesis de España, y reunidos aquí se conocerán y amarán... y así se formará entre ellos un lazo de fraternidad que les moverá a trabajar luego en mancomunión por la gloria de Dios...

Pretendemos constituir con los colegiales de San José de Roma un compacto apostolado para la promoción de los intereses de Jesús. Acariciamos, en fin, la esperanza de que este Colegio..., secundado por los colegios y colegiales de España, pueda ser capaz, con la gracia de Dios, de renovar nuestra España.

\subsection{Proyecto pastoral inmediato y universal}

Y no debe extrañaros estas afirmaciones... De aquí a unos años, si Jesús lo bendice, nuestros operarios verán esparcidos en las parroquias centenares, tal vez miles de sacerdotes formados en el espíritu de propaganda y reparación. Entonces toda obra de Dios podrá ser promovida fácilmente... y para impulsar cualquier obra señalada como necesaria o indicada por la Santa Sede o propuesta por el Episcopado como de conveniencia general...

¿Por qué fracasan hoy tantos proyectos saludables acordados en los congresos católicos, de reconocida utilidad y acogidos con entusiasmo?

Porque falta el impulso de una acción general constante y que pueda ser inmediata. Los prelados, para secundar estos proyectos, los dan a conocer y los recomiendan en sus boletines, y aun nombran juntas, y éstas oficialmente le presentan y cumplen su encargo por deferencia; y sólo obtienen algún resultado los que tienen la fortuna de tropezar con algún individuo de celo que por su iniciativa personal quiera promoverlos.

Se echa de menos el impulso de una acción inmediata y universal que los coadune, y esta acción no podrá ejercerla una Institución por distinguida y apostólica que sea, si no está por naturaleza e índole en contacto permanente con el clero. 


\subsection{Unión del clero}

A esta empresa que nos proponemos de unión sacerdotal y de movimiento de celo para la propaganda del bien, vimos que podíamos contribuir más que ninguna otra, y ser como el nervio de ellas, los jóvenes salidos del Colegio de Roma; y esto no sólo por la facilidad de relaciones entre sí adquiridas durante su estancia fraternal en Roma, sino porque serían destinados, ¿para qué ocultarlo?, a desempeñar cargos y ocupar destinos de más responsabilidad, sí, pero también de más trascendencia, y que por lo mismo los pondría en situación de poder influir con más eficacia en los resultados de la propaganda del bien...

A esa acción universal y a ese movimiento y unión de celo aspiramos; y éste ha sido uno de los móviles que nos han impulsado a la formación de este Colegio, como medio eficacísimo para ello...

\subsection{No solo una utopía}

Y no creáis que esa santa ambición sea una apreciación utópica, una ilusión hija de nuestro buen deseo. Esto lo estamos tocando en pequeña escala, o mejor dicho parcialmente; en nuestra diócesis de Tortosa tenemos esparcidos por las parroquias unos ciento cincuenta sacerdotes hijos de nuestro Colegio... casi todos se sienten unidos a nuestra Obra con lazos de afecto y de cierta cariñosa dependencia que les produce el carácter paternal de la misma consagrada al bien de la juventud eclesiástica...

Esta influencia parcial puede nuestra Hermandad lograrla generar en el clero, por el carácter sacerdotal de la misma y por sus objetos; y la misma ejercerá sobre vosotros...

\subsection{Miembros de una familia}

Visto lo que significa esta obra y los fines que nos proponemos, no extrañéis lo que hemos indicado antes, a saber: que al venir aquí vosotros, al pertenecer a esta obra, aun sin haberla antes conocido, adquirís un carácter distinto de el de simples individuos de un internado eclesiástico, puesto que es otro el concepto que entraña para nosotros y más para vosotros el nombre de Colegio de San José. Porque con él y para él entráis a formar parte de una Institución. Venís a ser miembros de una familia que no está circunscrita a los límites de esta casa, sino que abraza a todos los jóvenes levitas que deben informarse y se informan en el mismo espíritu sacerdotal bajo el manto de San José, y con los cuales os unen desde ahora los lazos de una verdadera fraternidad. 


\section{VIDA INTERNA}

\subsection{Criterios}

Digamos de entrada que el fundador del Colegio no era muy amigo de reglamentos escritos:

El reglamento particular depende de la palabra y disposiciones de los superiores y las circunstancias pueden obligar a modificarlo... la experiencia tendrá que indicarnos lo que sea más eficaz para el bien de los alumnos.

Para entender su pensamiento, debemos recordar lo que el prescribía a sus operarios como apoyo para su vida sacerdotal y como sistema formativo: la vida en grupo, el trabajo en equipo, la presencia continua entre los alumnos, la reunión diaria para valorar y planificar la vida del centro.

Lo que sí señala claramente el fundador son las condiciones fundamentales para convivir en el Colegio y los medios para conseguir una convivencia familiar. Entre los primeros señala: contentamiento, igualdad y docilidad. Él mismo los explica a los colegiales:

Contentamiento: en una familia, aunque sea pobre, todos están contentos de pertenecer a ella... no envidiarán las otras... no quisieran pertenecer a otras más ricas, si tuvieran que abandonar la propia. Ved el niño... si hay poco se contenta, y si hay mucho se alegra. Si hay deficiencias y estrecheces no murmurarán ni se irá a manifestarse a extraños... sino que lo sufrirá en el seno de la misma.

Igualdad: en una familia no se miran las ocupaciones de cada uno... están contentos en lo que a cada uno toca hacer o se señala y están prontos a ejecutar lo que conviene para el bien de la casa... no hay ningún oficio ni ocupación humillante.

Docilidad: prontitud, son las condiciones que debe revestir el afecto a la obra... tal vez haya deficiencias en esta casa; pero no debe olvidarse que no será por falta de afecto y buena voluntad.

\subsection{Medios}

Seguidamente les indica cuáles eran, a su parecer, los medios para el cumplimiento de estos deberes:

La aplicación al estudio, la verdadera piedad y un comportamiento digno de aquí y después al volver a vuestras diócesis. 
Después de dar los motivos que exigen estos medios, vuelve la mirada el fundador al panorama español:

El clero español hoy no tiene un gran nombre. Se le tiene sí por clero de sanas ideas y de carácter resuelto y animoso, pero revestido de cierta dureza, como si fuera gente más bien dispuesta a ser guerrilleros que a la mansedumbre del ministerio sacerdotal. Y quiera Dios que por otros no se nos mire como participantes del carácter que infundadamente se pinta de nuestro país.

\subsection{Responsabilidad compartida}

Termina sus charlas a los colegiales, el buen fundador del Colegio, con una llamada a la responsabilidad: de ellos depende el presente y el futuro del Colegio:

De vosotros y de los primeros que vayan viniendo depende el resultado, puesto que sois las primicias y los que han de producir las primeras impresiones, según sea el crédito y desarrollo que adquiráis, y las primeras impresiones difícilmente se borran...

En vuestras manos está el crecimiento o paralización de esta empresa, según el crédito que adquiráis, y con ello poder o no aportar una piedra al buen nombre de España; sois, pues, dueños de nuestro porvenir. Si queréis podéis arruinarlo.

Tales son los deberes y la responsabilidad que pesan sobre vosotros; y tal es la misión honrosa a la que por beneficio de Dios sois llamados, y que podéis llenar con la gracia si sois fieles a vuestra vocación, y no olvidéis cumplir y aprestaros a las instrucciones que me he creído en el deber de exponeros en la confianza de que no serán infructuosas, ni para vosotros, ni para los que vayan viniendo, a los cuales debéis transmitir estos sentimientos y estos conceptos.

Con estos criterios y estos medios señalados por el fundador comienza a caminar el Colegio. Los directores querían conseguir elevar el nivel intelectual y al mismo tiempo que no hubiera diferencias entre los alumnos. No era del todo fácil conseguir lo segundo, pues algunos llegaban a Roma con ideas no demasiado claras de lo que era el Colegio.

Por ello, ya desde el principio, pensaron los responsables en la selección del alumnado, en su participación en la organización interna del Colegio y en la necesidad de exigir que todos los alumnos fueran enviados por sus prelados. 
La selección del alumnado, la atención personal a cada uno de ellos por parte de los formadores, el nivel de vida espiritual y la altura académica se deja sentir muy pronto en el ambiente general de la casa. Una lectura comparada de las Memorias que el rector del Colegio elabora a final de cada curso nos da el punto exacto en que se encuentra el grupo.

Dentro de estos parámetros hay que colocarse para entender el interés de Merry del Val y de los Operarios en que los colegiales del Español realizaran sus estudios en la Universidad Gregoriana; en conseguir el reconocimiento de estudios de Roma por parte de las autoridades académicas españolas, así como las actividades complementarias que se organizan en el mismo centro o en los tiempos de vacaciones: lenguas modernas, música, teatro, formación literaria y otras.

Como colofón de esta primera etapa de la historia del Colegio, señalemos que con fecha 16 de diciembre de 1904, el Papa Pío X le concede el título de Pontificio ${ }^{19}$.

\section{EL PONTIFICIO COLEGIO ESPAÑOL, INSTRUMENTO EFICAZ PARA LA RENOVACIÓN DEL CLERO Y DE LOS SEMINARIOS ESPAÑOLES}

En abril de 1892, dos días después de la humilde inauguración del Colegio, escribía el fundador:

Si Jesús bendice esta empresa, veo clarísimamente todos los resultados de gloria de Dios que puede dar. Roma puede ser punto céntrico para formar una falange de sacerdotes, que luego puedan promover en España los intereses de la gloria de Dios en las Diócesis 20.

Terminado el primer curso, curso de ensayo como podemos llamarle, les dice a sus Operarios en la reunión de Valencia:

El Señor ha hecho desaparecer la montaña que separaba a la juventud eclesiástica de España de los Centros científicos de Roma; obra que ha de ser, si Dios lo bendice, la restauración científica y aun disciplinar del clero español21.

19 Roma. Archivo Hermandad. Fundador, II, 5, 35 y $5^{\circ}, 40$.

20 lbidem, $5^{\circ}, 38$

21 Ibáñez Arana, Los frutos del Colegio en recuerdo de unas fiestas. Roma, 1942, 147-150. 
Así lo esperaba también monseñor Vico, auditor en la Nunciatura de España, en su informe sobre la situación de los seminarios de España. El año 1942, al celebrarse los 50 años de la fundación, escribía uno de los antiguos alumnos:

Párrafo aparte y muy preferente merece la labor de los colegiales en los seminarios. Para entenderla hemos de volver la mirada a lo que el año 1892 eran los seminarios españoles en el espíritu sacerdotal, en los estudios, en la disciplina, y lo que son ahora. Si nos preguntamos la explicación de este bendito cambio, esperanza la más firme de la Iglesia española, seguramente que nos la darán en buena parte los 313 ex colegiales que han sido rectores, prefectos de estudio, profesores y superiores de seminario. Y diría que este ha sido el apostolado más típico, más delicado y más fructuoso de los colegiales romanos 22 .

Recordemos que por el Colegio de Roma pasó también el fundador del Seminarios de Misiones Extranjeras de Burgos, Emilio Rodero Reca, deán y vicario general de su misma diócesis de origen y rector del mismo seminario por él fundado en la ciudad de Burgos23. (21).

Intentando una síntesis sistemática, dejemos constancia de la tarea de los colegiales en las siguientes áreas formativas:

\subsection{En el aspecto científico}

Unió a España con la gran corriente de estudios de Roma:

- $\quad$ Ya en 1942, el catálogo de alumnos han salido 15 rectores, 140 profesores y superiores, muchos de ellos prefectos de estudio;

- $\quad$ La fundación de la Asociación para el fomento de los Estudios Bíblicos de España;

- $\quad$ La creación, poco tiempo después, también por ex colegiales de Roma, de la Casa de la Biblia, de los Cursos y Semanas Bíblicas, así como de una versión nueva de la Biblia. En esta misma línea otro grupo de especialistas en estudios de la Biblia, en su gran mayoría procedentes del mismo centro y bajo la dirección de uno de ellos, acaban de ofrecernos la nueva versión de la Biblia con sus comentarios correspondientes;

- Las múltiples actividades de la Biblioteca Balmes de

22 Emilio Rodero Reca, figura con el número 0258 en el Catálogo del Colegio.

23 González Martín, M.: Don Enrique de Ossó. Barcelona, 1967, 186-187. 
Barcelona con sus publicaciones, sus cursos de alta cultura religiosa y su prestigiosa revista;

- $\quad$ En el campo de las revistas, enumeremos: Revista Eclesiástica, Reseña Eclesiástica, Revista Española de Teología, Estudios Bíblicos...y en otro tono: Estría, Vida Nueva;

- $\quad$ El fomento de las semanas de Estudios Eclesiásticos y un cúmulo de publicaciones cuya sola enumeración desborda totalmente los límites de este comentario;

- $\quad$ Señalemos, finalmente, el fomento ya en el Colegio del estudio de lenguas modernas y los cursos ofrecidos para la renovación del clero.

\subsection{En el campo formativo}

- $\quad$ La influencia del estilo formativo marcado en el Colegio de Roma se advierten claramente en la redacción de los Reglamentos de los seminarios españoles que se elaboran a raíz de la aprobación del Código de Derecho Canónico;

- $\quad$ La idea de la necesidad de una gran selección del alumndo, tal como se aprecia en la Memoria del curso 1895 - 96;

- La atención personalizada a cada uno de los colegiales, pieza clave en esta área formativa será la importancia de la vida y trabajo en equipo de los formadores con las consecuencias lógicas de la presencia continua, el estudio de la maduración vocacional de cada persona;

- $\quad$ Los antiguos colegiales llevarán a sus seminarios las consignas oídas y practicadas en Roma: aplicación al estudio, verdadera piedad y comportamiento digno siempre;

- $\quad$ También se trasladarán con el tiempo la división de la gran comunidad en distintas secciones para un mejor acompañamiento de los alumnos en la organización de la vida interna del centro.

\subsection{En la espiritualidad}

- $\quad$ El fundador pide, desde los orígenes, piedad verdadera como algo constitutivo del Colegio. Y como prueba de esta importancia, una de las primeras y continuas preocupaciones del mismo fundador y luego de sus continuadores, fue la de dotar al 
Colegio de uno o varios directores espirituales;

- $\quad$ El fomento de la frecuencia en recibir los sacramentos, especialmente la confesión semanal y la comunión diaria;

- $\quad$ Los actos de piedad anuales, mensuales y diarios serán los que vamos a encontrar en todos los reglamentos de los seminarios españoles: los ejercicios espirituales, el retiro mensual, la misa diaria, el rezo del rosario, la oración personal en las primeras horas de la mañana;

- La insistencia en la espiritualidad eucarística como distintiva del clero, la fiesta del Reservado -aniversario de la inauguración de la capilla y de la permanencia continua del Sacramento en la casa-, la Hora santa de la noche del jueves, la Exposición del Santísimo todas las tardes de los domingos y grandes fiestas...;

- Nota especialmente atendida en el Colegio fue la esmerada preparación litúrgica y musical de los colegiales y de todos los actos tanto internos como en las actuaciones fuera del recinto colegial.

Podemos decir que el beato Manuel Domingo y Sol y Benjamín Miñana, fundador y rector primero respectivamente, dieron al Colegio un tono caracterizado por estos tres elementos: clima familiar, estudio serio y piedad profunda.

Dice un antiguo alumno, y con su testimonio cerramos este apartado: Del Altemps, miles de sacerdotes guardamos huellas profundas: fuimos allí estudiosos, píos y además felices.

\section{MÁS DE UN SIGLO DE SERVICIO}

Los 11 colegiales del curso de ensayo fueron multiplicándose. También la representación de las diócesis. En la que podemos llamar primera época, correspondiente a los años 1892 al 1909, la trayectoria es continuamente ascendente hasta llegar a los 104 del curso 1908 -1909; las diócesis presentes con alumnos en el Colegio llegaron a 54.

Desde la fecha señalada hasta el curso 1935 - 1936 se sostiene el número se mantiene la representación de las diócesis, el alumno va oscilando entre 75 y los 90 con el descenso explicable del curso 1818 -1919 debido a la situación política de Europa. 
Una bajada notable de aprecia a partir del 1937 que se prolonga hasta el curso 1945 -1946. Todos tenemos en la memoria la guerra civil española y la desolación de Europa en los años siguientes que se corresponden con la segunda guerra mundial. El Colegio fue lugar de acogida para instituciones españolas: alimentos, residencia, gestiones de todo tipo. Un pergamino elegantemente encuadrado y que se conserva en el archivo del Colegio es testigo del agradecimiento de todos al corazón grande de don Jaime Flores Martín.

A partir de 1947 fue creciendo el número de colegiales en correspondencia al resurgir espléndido de vocaciones sacerdotales en España. De los 99 alumnos del curso 1948 - 1949 se llega a los 129 del curso 1957 - 1958. El palacio Altemps ya no daba para más a pesar de los arreglos continuos.

El 1 de junio de 1951 la Congregación de Seminarios y Universidades aprueba los Estatutos del Colegio.

En el año 1952 se comienza a pensar en la necesidad de una nueva sede. En el 1955 se adquieren los terrenos sobre los que se levanta la actual sede del Colegio en la calle Torre Rossa. El 12 de octubre de 1956 se bendice y coloca la primera piedra. Jaime Flores deja la rectoral del Colegio en el verano del 1957 al ser designado director general de los Operarios Diocesanos. Tres años más tarde será nombrado obispo de Barbastro. Las obras del Colegio comenzarán el 24 de junio de 1959. Ya eran los tiempos de Juan XXIII y el rector Germán Mártil.

El 13 de octubre de 1961 los seminaristas se trasladan al nuevo edificio; los sacerdotes siguen residiendo en Altemps. Pablo VI inaugura oficialmente la nueva sede el 23 de noviembre de 1965. Los cursos entre 1962 y 1967 funciona en Colegio con dos sedes: un centenar largo de seminaristas en Torre Rossa y alrededor de 80 sacerdotes en Altemps. El curso 1967 - 1968 ya están todos en la sede única y actual.

En la primavera de 1970 los obispos españoles dan los últimos pasos y devuelven el palacio Altemps a la Santa Sede. Durante setenta y cinco años había sido Colegio Español de San José de Roma. Hoy se puede contemplar en su originalidad convertido en museo de escultura, conservando su espléndida capilla y otras estancias que fueron rincón de estudiantes españoles en Roma.

Nuevamente se deja sentir el descenso numérico del alumnado al comienzo de la década de los años setenta. En España la caída de las vocaciones es muy sensible y tiene su natural repercusión en el Colegio. Los años postconciliares, además de sufrir el descenso numérico, el Colegio vició los vaivenes que zarandearon al clero y a los seminarios españoles. Germán González y Antonio Castro rectores entonces, fueron 
testigos cualificados y a quienes les tocó llevar el timón sin que la obra se fuera a pique. Los ochenta fueron cursos de mayor serenidad y el rector Julio García contribuyó a hacerlo crecer en interioridad.

En el curso 1991 - 92, año del centenario de la fundación, el catálogo del colegio con 85 alumnos, nos ofrece los siguientes datos:

- 104 mártires entre superiores y colegiales,

- 85 obispos, de ellos 8 cardenales,

- $\quad 2.835$ colegiales

- de ellos 2460 sacerdotes.

En ese momento estaba de rector José María Piñero y había comenzado un nuevo servicio, los Cursos de Actualización Sacerdotal que continúan en la actualidad y por los que han pasado ya unos 600 sacerdotes españoles.

Durante los últimos años, 1993 a 2007, el número de colegiales fue creciendo hasta llegar a 118 en el curso que cerraba el siglo XX. Se ha cultivado la formación intelectual completada con otras ofertas que potencian la actualidad científica, la literatura, el arte y de forma especial la música.

Al celebrar el centenario de la muerte del fundador, el Colegio hace su carta de presentación con datos sobresalientes de sus colegiales:

- $\quad$ El catálogo ha llegado a 3.432 colegiales,

- $\quad$ La Iglesia española y la misma sociedad se ha enriquecido con la incorporación de unos 400 doctores en distintas especialidades.

- $\quad$ Los licenciados son casi innumerables.

\section{EL COLEGIO ESPAÑOL DE ROMA, OBRA SIGNIFICATIVA DEL BEATO MANUEL DOMINGO Y SOL}

Insiste repetidamente el fundador en sus escritos en la idea de que la renovación de la Iglesia española y de la misma nación vendrá por la renovación del clero. Por eso, refiriéndose al Colegio, no duda en escribir:

Pretendemos constituir con los colegiales de San José de roma, un apostolado compacto para la promoción de los intereses de Jesús. Acariciamos la esperanza de que este Colegio pueda ser capaz, con la gracia de Dios, de renovar nuestra España. 
León XIII había apuntado en la misma dirección cuando al ceder el palacio de los Altemps para sede del Colegio, escribía: ...el principal cuidado de la Santa Sede había sido restaurar los seminarios españoles como morada de piedad y de instrucción... a cubrir este vacío venía el Colegio Español de Roma.

¿Fue un sueño el que tuvo Manuel Domingo y Sol o cumplió sus objetivos?. Tomemos solamente un breve manojo de testimonios.

- Uno de los antiguos colegiales, con el lenguaje de hace más de medio siglo, confiesa: lo que no ofrece lugar a duda ninguna es que Don Manuel, formado en el ambiente de los seminarios españoles de entonces, que, debido a las conmociones políticas de la época, era deficiente y anémico en todos sus aspectos... concibió tan perfectamente la idea integral de la fundación romana, que la vio desde luego enmarcada en sus cuatro perfiles fundamentales, inmutables, definitivos: escuela de selecta virtud, centro de cultura, venero de romanidad, obra del más elevado patriotismo.

- $\quad$ Si es cierta la afirmación del cardenal González Martín que en su momento escribió sobre el fundador del Colegio: $A$ don Manuel le cabe la honra indiscutible de haber sido el primer eclesiástico español que concibió y realizó un plan a gran escala para reformar por completo el sombrío panorama de los seminarios españoles, no está fuera de lugar que afirmemos que uno de los medios más eficaces de que se sirvió para esta labor de reforma fue la fundación y sostenimiento del Colegio Español de Roma24.

- Los testimonios de Pablo VI son repetidos aprovechando momentos de la historia del Colegio. Tomemos el que emitió con motivo del 75 aniversario de su fundación: bien conocemos la trascendencia que este centro ha tenido para la vida religiosa de la dilectísima nación española a la que ha enriquecido con sacerdotes que dieron y siguen ofreciendo ejemplar testimonio de virtudes ministeriales y de competencia científica.

- $\quad$ Juan Pablo II: El 29 de octubre de 1983 en la homilía de la celebración de la palabra durante su visita al colegio: El Venerable sacerdote de la diócesis de Tortosa, Manuel Domingo y Sol avezado en su interior al coloquio divino, con amor de hijo, tuvo la inspiración de fundar este Colegio, hace noventa años, aquí, en Roma, junto a la Sede de Pedro.

24 Javierre, J.M., O. C., 289. 
La labor realizada en su ya casi un siglo de existencia por el Colegio Español es una magnífica y consoladora realidad que merece el reconocimiento y la gratitud de la Santa Sede y de todo el Pueblo de Dios. Y este reconocimiento va, en primer lugar, a la Hermandad de Sacerdotes Operarios Diocesanos del Corazón de Jesús, fundada también por el mismo don Manuel Domingo y Sol, la cual tiene confiada por la Santa Sede la dirección de este Cenáculo sacerdotal.

19 de marzo de 1992 en la carta con motivo del primer centenario de la fundación del Colegio: Después de este siglo de vuestra historia no ha sido vana la esperanza de los fundadores, que quisieron el Colegio como una siembra de buenos frutos para las Iglesias de España. Entre estos frutos me es grato recordar los antiguos alumnos que honraron a la Iglesia en el servicio del episcopado; también el elevado número de alumnos, que han dedicado su trabajo durante tantos años a la formación de los seminaristas, principalmente de España; por fin recordamos a aquellos que ofrecieron el ejemplo de sus virtudes en el ministerio pastoral y en el derramamiento de su sangre sacerdotal.

El 1 de diciembre de 2000 en la audiencia a la comunidad, con motivo del V Centenario del nacimiento de San Juan de Ávila, patrono del clero español: El Colegio Español os acoge a cada uno de vosotros, enviado por el propio Obispo, para enriquecer la propia Iglesia local con una formación académica más amplia y una experiencia más universal de la Iglesia.

Don Manuel no había soñado. León XIII veía cumplidos sus deseos y por ello escribe al ceder para sede del colegio el palacio Altemps, ... con la esperanza de copiosos frutos, había resuelto favorecer el Colegio recientemente fundado en Roma para los seminaristas de España, merced al iluminado celo de algunos piadosos sacerdotes.

Como escribe uno de los biógrafos del fundador, el Colegio Español ha sido la "oficina" soñada por Mosén Sol para preparar científicamente sacerdotes que levantaran el nivel de nuestros seminarios (23). A fin de que esta fábrica funcionara les dice a los Operarios responsables de su dirección: quiero todo para el Colegio; para nosotros, el trabajo y el quebranto.

Ya metidos de lleno en el siglo XXI el Colegio sigue en su tarea y se renueva no sólo en su estructura externa sino en el ambiente cultural, espiritual y humano con la incorporación de nuevos colegiales llegados de las diócesis españolas cada año y con la apertura a otras iglesias, especialmente de América Latina. 
Manuel Domingo y Sol se sentiría satisfecho, en el centenario de su muerte, al pasar su mirada por el Catálogo del Colegio y ver afirmadas sus ideas en la definición del mismo:

- La finalidad del Colegio es procurar un clima espiritual, científico, material y de convivencia apto para la formación integral de los alumnos que vienen a Roma con el fin de realizar estudios superiores eclesiásticos;

- $\quad$ El Colegio intenta hacer viva y real entre los sacerdotes residentes la íntima fraternidad sacerdotal;

- Los alumnos cultivan como señales de identidad:

- Un elevado espíritu sacerdotal y apostólico;

- Una constante inquietud científica a favor de la misión;

- Un gran sentido de Iglesia universal y particular.

La Fundación del Pontificio Colegio Español de San José de Roma, unido íntimamente a la Asociación Sacerdotal: Hermandad de Sacerdotes Operarios Diocesanos del Corazón de Jesús es tal vez la obra más significativa del ministerio presbiteral del Beato Manuel Domingo y Sol. Con ella colabora eficazmente a la renovación integral de los seminarios y del clero y completa su obra de los Colegios de Vocaciones Eclesiásticas para el fomento, cultivo y sostenimiento de las vocaciones, especialmente de las sacerdotales. 